\title{
Conceptual metaphors are not automatically accessed during idiom comprehension
}

\author{
SAM GLUCKSBERG, MARY BROWN, and MATTHEW S. MCGLONE \\ Princeton University, Princeton, New Jersey
}

\begin{abstract}
Do conceptual analogies motivate idiom use and comprehension in discourse? For example, a story in which a person is described as fuming would be analogically consistent with an idiom such as blew her top, but inconsistent with an idiom such as bite his head off. Earlier work by Nayak and Gibbs (1990) had suggested that people use such analogical information during idiom comprehension. We replicated their findings in an idiom choice task, suggesting that people can indeed make use of such knowledge. However, when reading times were used to assess idiom comprehensibility, no effects of analogical consistency were found. We conclude that conceptual analogies play little, if any, role in idiom comprehension unless people have the time (and motivation) to make considered judgments.
\end{abstract}

Idioms are typically described as frozen phrases whose meanings are stipulated directly in a mental lexicon. Thus, the meaning of a phrase such as to kick the bucket would be represented in an idiom or phrasal lexicon simply as "to die" (Bobrow \& Bell, 1973; Swinney \& Cutler, 1979). Many idioms, however, are more complex and dynamic. Consider, for example, idioms such as carrying coals to Newcastle or locking the barn door after the horses have been stolen. Such idioms may well have meanings stipulated in a phrasal lexicon, but they are also recognized as alluding to prototypical instances of the concepts that they refer to (Glucksberg, in press). Thus, these idioms are fully compositional in that they are both semantically and syntactically productive. One can, for example, say, in reference to the savings and loan scandal of this decade, "they never did lock the barn door until after the barn was stolen." Such novel and productive twists on idioms are understood easily by anyone familiar with the original idioms (Glucksberg, 1991; McGlone, Glucksberg, \& Cacciari, in press).

Another class of idiomatic expressions may also require fairly complex representational assumptions. Expressions for many abstract concepts seem to cluster in terms of underlying conceptual analogies. Thus, we speak of time in spatial terms, of relationships with others as journeys, of success and failure as directions of movement (Kovecses, 1986; Traugott, 1975, 1985). Many such abstract concepts can be conceptualized in systematically different ways. Anger, for example, can be conceptualized in any one of several specific ways (Lakoff, 1987; Lakoff \&

We are grateful for the financial support provided by Public Health Service Grant HD 25826 to Princeton University. We also thank Ray Gibbs for providing us with both his insights and his materials, and Susan Fussell, Boaz Keysar, Deanna Manfredi, and Sachi KumonNakamura, for their valuable comments and suggestions. Correspondence should be sent to S. Glucksberg, Department of Psychology, Princeton University, Princeton, NJ 08544-1010.
Johnson, 1980). One conceptual metaphor for anger is that of a heated fluid under pressure. Idioms that seem to reflect this conceptual metaphor include flip your lid, let off steam, blow your top, and get hot under the collar. An alternative conceptual metaphor for anger is that of animal-like behavior, reflected in such idioms as bite someone's head off and jump down someone's throat. Although broad conceptual metaphors or analogies seem to motivate many idiomatic expressions, their functional role in idiom use and comprehension remains unclear. When people encounter an idiom such as blow his top in a conversation, is the conceptual analogy of anger as heated fluid under pressure (1) available or (2) accessible? By availability, we mean that a conceptual structure is represented in semantic or long-term memory and could be retrieved under some, but not all, circumstances. By accessibility, we mean that a conceptual structure not only is available, but also can be accessed in a particular context to participate in either the production or the comprehension processes (for a fuller discussion of the availability-accessibility distinction, see Higgins, Rholes, \& Jones, 1977; Srull \& Wyer, 1979).

By definition, the availability of a conceptual structure is context independent: it is either stored in memory or not. Again by definition, the accessibility of any specific conceptual structure is context dependent. Any given item in memory may be accessible in one context, but not accessible in another. For example, if there is a conceptual analogy of anger-as-fluid-under-pressure in semantic memory, this conceptual structure is available. It may be accessible in some circumstances, but not in others. Thus, it might be accessible and used when people have the time to make considered, deliberate judgments. It might, however, be inaccessible and therefore not used in ongoing speech comprehension and production when people do not have the time for such judgments. In the work to be presented here, Experiment 1 asks whether people access conceptual analogues when making considered judgments 
about idioms. Experiments 2 and 3 ask whether people have [automatic] access to such analogical information under conditions of speeded reading for comprehension.

There is some evidence that people do use conceptual analogical information when the situation is conducive to deliberate judgments. Nayak and Gibbs (1990, Experiment 6) asked college students to judge the appropriateness of idioms in specific contexts. The students were given short narratives such as the following (emphases added):

Mary was very tense about this evening's dinner party. The fact that Bob had not come home to help was making her fume. She was getting hotter with every passing minute. Dinner would not be ready before the guests arrived. As it got closer to five o'clock the pressure was really building up. Mary's tolerance was reaching its limits. When Bob strolled in at ten minutes to five whistling and smiling, Mary. .

\section{blew her top. \\ bit his head off.}

In this story, the protagonist's (Mary's) anger is described in terms of increasing pressure and heat- "making her fume," "getting hotter," "pressure was really building up," and so forth. The story is thus stylistically consistent with idioms that could instantiate the concept of anger as heated fluid under pressure-in this case, blew her top. The following scenario was constructed to be consistent with an alternative conception of anger, that of animallike behavior (emphases added):

Mary was getting very grouchy about this evening's dinner party. She prowled around the house waiting for Bob to come home to help. She was growling under her breath about Bob's lateness. Her mood was becoming more savage with every passing minute. As it got closer to five o'clock, Mary was ferociously angry with Bob. When Bob strolled in at 4:30 whistling and smiling, Mary...

blew her top.

bit his head off.

Here, the description of Mary's behavior in bestial terms- " "prowled," "growling," "savage," and so forth-is consistent with idioms that instantiate animallike behavior, such as bite his head off.

Consistent with the hypothesis that idiomatic conceptual analogies are available and accessible when people have the time to make deliberate judgments, the students rated analogically consistent idioms as more appropriate than comparable but analogically inconsistent idioms. Thus, blew her top was rated as more appropriate as a completion when anger was described in heat and pressure terms, and bit his head off as more appropriate when anger was described in bestial terms.

On the basis of this finding, Nayak and Gibbs (1990) concluded that readers not only have relevant conceptual information available, but also use this information to facilitate idiom comprehension. The differences in appropriateness ratings are taken to reflect the relative difficulty subjects had in interpreting the competing idiom completions. Idioms in story contexts that were matched for analogical information were considered easier to interpret than idioms in contexts using a different conceptual analogy. The appropriateness ratings, on this account, directly reflected on ease of interpretation.

There are, however, at least two additional competing interpretations of these data. First, the appropriateness ratings may not be the product of ease of comprehension at all, but rather the outcome of postcomprehension decision and judgment processes. After all, people might readily notice the relation between pressure words in a text and the semantic content of an idiom such as blow one's top. If this were the case, the data might simply reflect the ability of people to recognize a relation between themes in a text. If the subjects in the Nayak and Gibbs experiment did recognize relations between textual elements and the idiom choices, their choices may have been based simply on a preference for stylistic consistency. Second, the data may not even implicate deliberate choices at all. As Kreuz and Graesser (1991) have pointed out, the ratings data may be entirely attributable to simple lexical priming rather than stylistic consistency per se. Words such as prowled, growled, and savage are semantically associated with the word bite, as in the idiom bite his head off. There is substantial evidence that inferences that readers draw during text comprehension can be strongly influenced by lexical priming (e.g., Ratcliff \& McKoon, 1986; Potts, Keenan, \& Golding, 1988). Thus, even if there were no conceptual analogy in semantic memory underlying the meaning of the idiom bite ones' head off, the relationship between the words in a text and the words in an idiom could influence subjects' appropriateness ratings.

Experiment 1 was designed to control for simple lexical priming by varying the referent of the target idioms. In the original Nayak and Gibbs (1990) materials, only the central protagonist in a story could be the referent of target idioms. We used these original materials as part of a replication of the Nayak and Gibbs study, but we also used two other item types. The first was an other-person referent version of the original story, in which the hypothetical conceptual analogy information referred to the original protagonist, but the target idioms referred not to that protagonist, but instead to some other person. Thus, if Mary were to be described as fuming in a particular scenario, the target idiom blow one's top would refer to another person, Chuck, in that scenario. If idiom appropriateness judgments are simply a function of which kinds of idiomatically relevant concepts are most accessible in a given context, the specific referent of the target idiom should make no difference. Thus, if anyone in a story is described in fuming-anger terms, anyone in that context would tend also to be described in those terms. To control for lexical priming per se, we used a third type of scenario, in which a situation or state of affairs, rather than any person, was described with words relevant to an idiomatic conceptual analogy - for example, the wind "roared." Such nonperson descriptions should not evoke any specific emotion concept such as anger, and so they 
should not elicit analogically consistent idiom judgments, unless the lexical items themselves prime such judgments. The target idioms referred invariably to a person in the scenario-for example, she bit his head off. If lexical priming were the only effective variable, subjects' judgments of idiom-story appropriateness should not be affected by an idiom's referent. Even when events or situations are described, say, in animalistic terms, subjects should judge that animal-consistent anger idioms are more appropriate than idioms based on other metaphors for anger.

To summarize the logic of Experiment 1, if judgments of idiom appropriateness are based on the specific emotion attributed to a specific protagonist in a given context, analogically consistent idioms should be chosen as most appropriate only in the original-person referent condition. If people base their choices instead on the basis of which emotion concepts are most accessible in memory in a given context, there should be no difference between the original- and the other-person referent conditions. Either of these two patterns of results would be consistent with the claim that people can use conceptual analogical information for idiom interpretation when such information is available. However, if readers' idiom preferences can simply be primed by the words in a story context, the same idiom preferences should be exhibited in all three types of stories. People should, for example, choose animal-behavior idioms to describe an angry person even when the story uses a word such as roar to refer not to anger, but instead to the sound of the wind. The latter result would support Kreuz and Graesser's (1991) contention that Nayak and Gibbs's findings are simply an artifact of lexical priming.

\section{EXPERIMENT 1 Idiom Choice as a Function of Analogical Consistency}

\footnotetext{
Method

Subjects. Twenty-four undergraduate students at Princeton University were paid for their voluntary participation. All were native English speakers, and none had participated previously in studies of figurative language.

Materials and Procedure. Nine idiom pairs, two each referring to the concepts of anger, fear, success, and failure were chosen as targets for appropriateness judgments. Each pair of idioms instantiated two alternative conceptual analogies for the concept of interest. For example, the idioms flip your lid and bite someone's head off presumably reflect two alternative metaphors for anger: heated fluid under pressure and animal behavior, respectively. The 18 context stories used by Nayak and Gibbs (1990, Experiment 6) were adapted for this study. Each story was written in two versions, one to (theoretically) activate one conceptual analogy, the other to activate the alternative analogy (see examples, Appendix A). This yields 36 story-idiom pair items. Three referent versions of each story were then prepared: (1) An original-referent version, in which the target idiom would refer directly to the person in the story who was described in terms analogically consistent with just one of the two alternative idioms. This version was essentially identical to the stories used by Nayak and Gibbs (1990); (2) An otherperson referent version, in which the target idiom referred to some
}

person other than the one described in the story as conceptually consistent with one of the two alternative idioms. This version controls for specificity of the conceptual analogue. If the conceptual analogue for, say, anger as heated fluid under pressure is specifically associated with person $A$ in a story, but the final idiomatic statement refers to person $B$, there should be no reason to choose a pressure-anger idiom over an animal-behavior-anger idiom. If, however, idioms are chosen on the basis of whatever idiomatic analogue is activated during the course of the story, pressure-anger idioms should be chosen, as in the original-referent condition. (3) The nonperson referent version, a condition to control for lexical priming per se. In this version, the words that were associated with the conceptual analogue of a target idiom referred to a nonperson entity in the story, such as the weather, as in the wind roared. In all three versions, the target idioms always referred to a person. Examples of these materials are presented in Appendix A.

The 36 story-idiom pairs each appeared in the three referent versions to provide a total of 108 experimental items. In addition to modifying the materials to provide the three different referent conditions, we also modified the experimental task. Nayak and Gibbs (1990) obtained ratings of idiom appropriateness. We decided to use a measure that more closely reflected discourse production processes: at the end of each story, the subjects were given a choice of two idioms and were asked to choose the idiom that best completed the story. In all cases, either idiom provided a sensible completion; for example, subjects could choose between flipped her lid and jumped down his throat to describe a protagonist's anger. In addition to providing a measure, albeit indirect, of idiom production, this alternative measure also provides a converging operation that could extend the generality of Nayak and Gibbs's findings.

The 108 experimental items were divided into six sets of 18 each. The sets were counterbalanced so that only one of the factor combinations for a story and idiom-choice combination appeared in a given set. The sets contained equal numbers of original-, otherperson, and nonperson referent stories. Each set of 18 experimental items was presented in a booklet along with 52 filler items, for a total of 70 items per booklet. The fillers, like the experimental items, were story and idiom-choice combinations, but the stories provided no apparent cues to guide idiom choice.

The subjects were randomly assigned to one of the six item booklets. They were instructed to read each story carefully and to choose the idiom they considered to be the more appropriate completion for each story. The subjects circled their choices directly in the questionnaire booklet. This procedure took about $1 \mathrm{~h}$, after which the subjects were debriefed about the purpose of the experiment.

\section{Results and Discussion}

The data of interest are the proportions of conceptually consistent idiom choices as a function of referent condition (see Figure 1). In the original-referent condition, the analogically consistent idiom was chosen $69.4 \%$ of the time. This percentage is significantly greater than chance $(p<.01$, binomial distribution). This finding replicates Nayak and Gibbs (1990), even though we used a different dependent measure-namely, forced choice instead of appropriateness ratings. In the other-person referent condition, 6 of the 24 subjects apparently noticed that the topic of the story had been abruptly switched, and on seven occasions they substituted the original-person referent for the switched-person referent by crossing out the other-person referent's name and writing in the original protagonist's name. On five other occasions (one occasion for 5 of these 6 subjects), either no choice was indicated, or the subject wrote "neither makes sense." The 


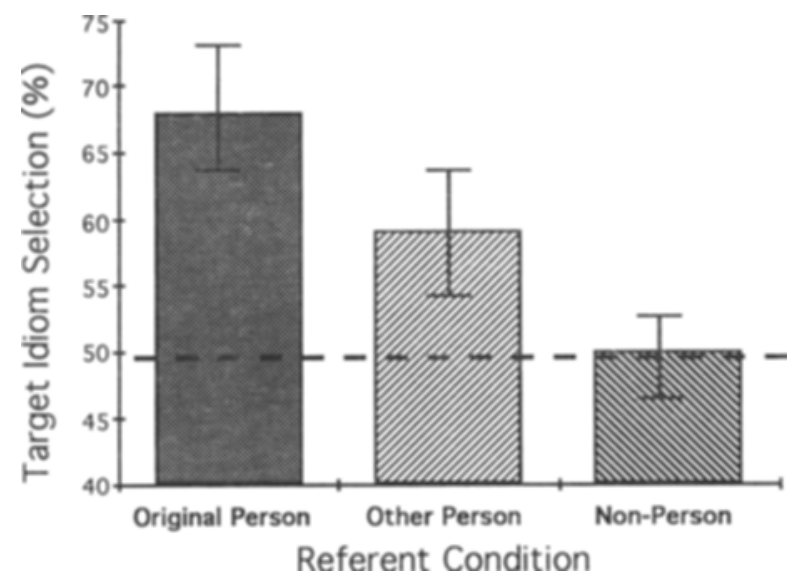

Figure 1. Idiom selection as a function of referent condition.

choice data for these 11 occasions were discarded from the analysis. The corrected data, as shown in Figure 1, indicate a preponderance of analogically consistent choices $(60.2 \%)$ in the other-person referent condition $(p<.05$, binomial distribution). These data strongly suggest that our subjects were generally sensitive to analogical consistency when a person in a story was described in idiomatically relevant terms, but that it did not matter much which person this was. This effect, however, is not simply attributable to lexical priming, because idiom choice was at chance level in the nonperson referent condition ( $50.93 \%$ analogically consistent). It seems that if a particular conceptual analogy is activated in a given context, idioms consistent with that analogy will be preferred when both the story context and the idiom involve a person referent. However, when the story context involves a nonperson referent and the idiom itself refers to a person, idiom choice is not affected.

This interpretation is consistent with an analysis of variance (ANOVA) of the choice proportions. A one-way repeated measures ANOVA, with both subjects $\left(F_{\mathrm{s}}\right)$ and items $\left(F_{\mathrm{i}}\right)$ as random factors, revealed a significant effect of referent condition $\left[F_{\mathrm{S}}(2,46)=5.42, p<.01\right.$; $\left.F_{\mathrm{i}}(2,54)=3.72, p<.05\right]$. Neuman-Keuls tests revealed that the proportions of analogically consistent choices differed between all three conditions $(p<.05)$ for the subjects analysis. In the items analysis, the only significant difference occurred between the original-person and nonperson referent conditions.

The most parsimonious interpretation of these data is that the conceptual analogues for an idiom are accessed only when the appropriate idiomatic concept itself (e.g., anger) is activated. Thus, when a person is described as fuming, anger idioms that are consistent with heated fluid under pressure, such as blow one's top, are preferred to inconsistent idioms. The particular person or persons involved do not seem to matter all that much, suggesting that the effective mediating factor is the general kind of idiom involved, not its specific referents. In contrast, when words such as fuming are used to describe nonperson entities, they presumably do not activate personrelevant concepts such as anger. This in turn implies that the choice patterns in our person referent conditions were not an artifact of lexical priming per se.

Conceptual analogical information thus seems to be accessible, at least when people make considered, nonspeeded judgments or choices. Is such information accessible during relatively unreflective comprehension? More specifically, is such information automatically activated when people are not asked for deliberate judgments but instead simply read for comprehension? Experiment 2 was designed to address this issue. If an idiom's hypothesized conceptual analogy is automatically accessed during comprehension, comprehension should be facilitated when an idiom is analogically consistent with prior text, as opposed to when an idiom is analogically inconsistent with that text. In Experiment 2, we used a speeded task rather than a reflective judgment task, and reading time was used to assess whether analogically consistent text-idiom relations facilitate comprehension.

\section{EXPERIMENT 2 Does Analogical Consistency Facilitate Idiom Comprehension?}

\section{Method}

Subjects. Thirty-two Princeton undergraduates served as paid volunteers. All were native English speakers, and none had previously participated in an experiment involving figurative language.

Materials and Design. The original-referent and other-person referent items of Experiment 1 were adapted for this experiment. Stimulus stories were created by combining original-referent and other-person referent versions of each story with one member of a given idiom pair. The particular idiom could be analogically consistent or inconsistent with the story context. This yielded four story conditions for each idiom. The context stories were edited so that they could be presented line by line on a computer screen. The sentence containing the target idiomatic phrase appeared either at the end of the story or as the next to the last sentence in the story (for examples, see Appendix B).

These materials were used in a $2 \times 2$ within-subjects design. The two factors were referent version (original vs. other-person) and analogical consistency between story and idiom (consistent vs. inconsistent). On the basis of the results of Experiment 1, we would expect that analogically consistent idioms would be read more quickly than inconsistent idioms irrespectively of referent condition, because specific kinds of anger should be activated in both conditions. The original-versus other-person referent comparison serves as a manipulation check, because switching the topic or focus of a story in midstream should disrupt performance (Garrod \& Sanford, 1988). Garrod and Sanford found that reading times were slowed when a story topic shifted in a text. If reading times in our task are not affected by a switch from original- to otherperson referents, this would indicate that our dependent measure (reading time) is simply not sensitive enough to detect differences in comprehension difficulty. The nonperson referent condition that we used in Experiment 1 to control for lexical priming per se did not lead to analogically consistent choices, so we elected not to use this condition in Experiment 2, in order to maximize the likelihood of finding an effect of analogical consistency.

Sixty-four stories ( 16 idioms $\times 4$ story conditions) were randomly assigned to one of four lists, so that only one of the story condi- 
tions for a particular idiom appeared on a given list. Each list contained 4 items of each story type for a total of 16 experimental items. Interspersed among the experimental stories were 16 filler stories, 3 of which appeared as practice items. These stories were adapted from the fillers of Experiment 2 by randomly selecting one member of the original idiom pair for each filler story. As with the experimental items, the sentence containing the idiomatic phrase appeared either as the last or the next to the last sentence of the filler stories.

Procedure. The subjects were randomly assigned to one of the four counterbalanced lists, with the constraint that all lists were used equally often. The stories were presented in a different random order for each subject. The subjects were seated in front of a Samsung MA 2565 monochrome monitor at a comfortable reading distance, with the right hand resting on the " +" key of the numeric keypad of an Epson Equity $1+$ computer. The stories were presented line by line at the center of the screen in standard upper- and lowercase type.

The subjects were given the following instructions:

In this experiment, you will read a number of very short stories, each about a paragraph long. These stories will appear on the screen one sentence at a time, at a pace that you will determine. When a line appears, read it, and when you are ready for the next line, press the gray plus $(+)$ key on the extreme right side of the keyboard. You should try to read the stories at a quick pace, but do not move to the next sentence until you have understood the sentence currently on the screen. Once you move to a new sentence, you will not be able to backtrack to any previous sentences.

The end of each story was signaled by the words "END OF STORY" following the last sentence. To advance to the next story, the subjects again pressed the " + " key. Reading times for each line were measured from the onset of the line to the keypress for advancing the next line.

Following four of the filler stories, true/false questions concerning the content of the preceding story were presented, for which subjects provided their answers on a paper-and-pencil score sheet. These questions were included to ensure that the subjects read for comprehension. After answering a question, the subjects pressed the " + " key to advance to the next story. On the average, the subjects took approximately $35 \mathrm{~min}$ to complete the experiment. They were then debriefed and told the purpose of the experiment.

\section{Results and Discussion}

All 32 subjects answered the content questions correctly. The data for these subjects were trimmed by excluding data points \pm 2.5 standard deviations from the relevant condition means. This eliminated only six of the observations $(<1 \%)$. No differences were found between analyses of the trimmed and untrimmed data, so we report only the analyses of the trimmed data. An initial ANOVA that included lists as a factor revealed a significant main effect of lists, but no significant interactions involving lists. We therefore report the results of analyses collapsing across this factor.

Mean reading times for the target idioms as a function of the referent and analogical consistency conditions are presented in Figure 2. Two-way ANOVAs were performed on these data with referent version (original vs. other person) and analogical consistency (consistent vs. inconsistent) as repeated within-subjects factors. Two such ANOVAs were done, one with subjects as a random factor $\left(F_{\mathrm{s}}\right)$ and one with items as a random factor $\left(F_{\mathrm{i}}\right)$.

Reading times were reliably slower in the other-person referent version than in the original version $(2,323 \mathrm{msec}$

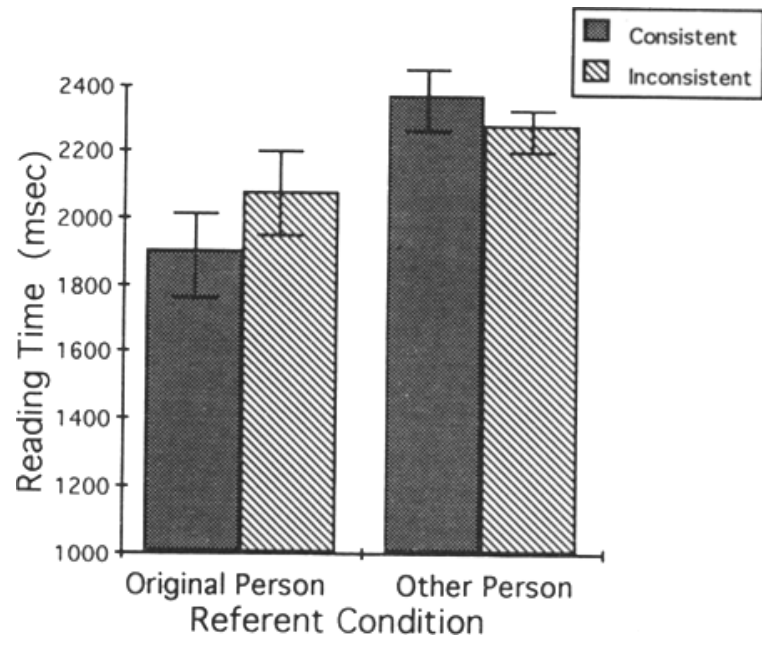

Figure 2. Mean reading times as a function of referent condition and idiom-text consistency, Experiment 2 (bars indicate standard errors of the means).

vs. $1,988 \mathrm{msec}$, respectively). This main effect of referent version is reliable $\left[F_{\mathrm{s}}(1,31)=12.62, p<.001\right.$; $\left.F_{\mathrm{i}}(1,15)=5.93, p<.05\right]$. This result is to be expected. The stories would lead readers to expect material that focused on the main protagonist. When the story shifts abruptly to another person, reading should be momentarily disrupted by the break in story coherence (cf. Garrod \& Sanford, 1988). Although expected, this result also provides a manipulation check on our method, indicating that the obtained reading times were sufficiently sensitive to permit the detection of variations in comprehension difficulty.

Analogical consistency had no discernible effect on reading times. The mean reading times for analogically consistent and analogically inconsistent idiom completions were $2,137 \mathrm{msec}$ and $2,174 \mathrm{msec}$, respectively. This difference was not reliable $\left[F_{\mathrm{s}}(1,31)=1.78, p>.05\right.$; $\left.F_{\mathrm{i}}(1,15)=.80\right]$. More importantly, the interaction of referent version and analogical consistency did not approach significance $\left[F_{\mathrm{s}}(1,31)=2.01, p>.05 ; F_{\mathrm{i}}(1,15)=\right.$ $.90]$. Even though we did not obtain a significant interaction, we performed $t$ tests on the difference between analogically consistent and inconsistent idiom conditions in the original-referent condition. The difference between these two conditions is $171 \mathrm{msec}$, roughly half the magnitude of the $335-\mathrm{msec}$ difference obtained for the original- and other-person referent conditions. The effect of analogical consistency within the original-person referent conditions did not approach significance $\left[t_{s}(31)=\right.$ $1.38, p>.16 ; t_{\mathrm{i}}(15)=1.01, p>.26$ ]. These results replicate those of Gibbs (1992), who reported a similar failure to find effects of analogical consistency on comprehension performance, as measured by reading times.

The absence of any main effects or interactions involving analogical consistency, together with a robust effect of referent version, suggests that even when a specific 
conceptual analogue for an emotion is available in a story, that conceptual analogue is not automatically accessed during idiom comprehension. Persons in a story may have been described, for example, as being angry in the hot and fuming sense, yet this did not facilitate the comprehension of an analogically consistent idiom such as blow one's top as opposed to a different and analogically inconsistent idiom such as bite someone's head off. As far as the reading times indicate, anger is anger. Our subjects apparently did not take advantage of any conceptual analogue consistencies between story elements and idiomatic expressions when comprehending those expressions.

There are, however, two possible reasons for treating these conclusions with caution. First, null findings are ultimately ambiguous, even when replicated across laboratories. Second, and perhaps more important, the particular set of conditions that we used in Experiment 2 may have effectively prevented the detection of analogical consistency effects. As indicated by the results of Experiment 1 , subjects found the other-person referent texts odd. These texts were odd enough to produce significantly elevated reading times in Experiment 2. There is the possibility that the disruptive effect of the other-person items in Experiment 2 produced enough variance in responses that any effects of analogical consistency in the originalreferent condition were simply undetectable in the resultant (statistical) noise.

Accordingly, we performed a third experiment with the original-referent condition to test for effects of analogical consistency on reading time, together with the nonperson referent condition to control for lexical priming effects. Recall that the nonperson referent stories contained scenarios in which a situation or state of affairs, rather than any person, was described by words that are associated with an idiom's conceptual analogy (see Appendix A). Because these stories did not involve an abrupt switch of topic, we did not expect them to have disruptive effects on reading times.

\section{EXPERIMENT 3: A Further Search for Analogical Consistency Effects}

\footnotetext{
Method

Subjects. Thirty-three Princeton undergraduates served as paid volunteers. All were native English speakers, and none had previously participated in an experiment involving figurative language.

Materials and Design. The original referent stories from Experiment 2 were retained for this experiment, and the nonperson referent stories from Experiment 1 were adapted for line-by-line presentation (see Appendix B). As in Experiment 2, stories were created by combining referent versions of each vignette with one member of a given idiom pair. The particular idiom could be analogically consistent or inconsistent with the story context. This yielded four story conditions for each idiom. The sentence containing the target idiomatic phrase appeared either at the end of the story or as the next to the last sentence in the story.

As in Experiment 2, the materials were used in a $2 \times 2$ design, with referent version (original vs. nonperson) and analogical consistency between story context and idiom (consistent vs. inconsistent) as within-subjects factors. The 64 stories ( 16 idioms $\times 4$ story
}

conditions) were randomly assigned to one of four lists, so that only one of the story conditions for a particular idiom appeared on a given list. Each list contained 4 items of each story type for a total of 16 experimental items. Interspersed among the experimental stories were the 16 filler stories used in Experiment 2, 3 of which appeared as practice items.

Procedure. The procedure in this experiment was identical to that of Experiment 2.

\section{Results and Discussion}

One of the subjects failed to answer all of the content questions correctly, so this subject's reading time data were discarded. The data for the remaining subjects were trimmed by excluding data points \pm 2.5 standard deviations from the relevant condition means. This eliminated 10 of the observations (less than $1 \%$ of the data). No significant differences were found between analyses of the trimmed and untrimmed data, so we report only the analyses of the trimmed data.

Mean reading times for the target idioms as a function of referent and analogical consistency conditions are presented in Figure 3. Two-way ANOVAs were performed on these data with referent version (original vs. nonperson) and analogical consistency (consistent vs. inconsistent) as repeated within-subjects factors. Two such ANOVAs were conducted, one with subjects as a random factor $\left(F_{\mathrm{s}}\right)$, and one with items as a random factor $\left(F_{\mathrm{s}}\right)$.

Reading times were slightly slower in the nonperson referent versions than in the original versions $(2,192 \mathrm{msec}$ vs. $2,126 \mathrm{msec}$, respectively). This difference, however, was not significant in either the subjects or items analyses $\left[F_{\mathrm{s}}(1,32)=1.57, p>.22 ; F_{\mathrm{i}}(1,15)=0.84, p>\right.$ .38]. As expected, the nonperson versions of the stories did not produce the disruption in reading time that was found for their other-person version counterparts in Experiment 2 , which contained clear breaks in narrative continuity. Thus, the use of the nonperson versions in this

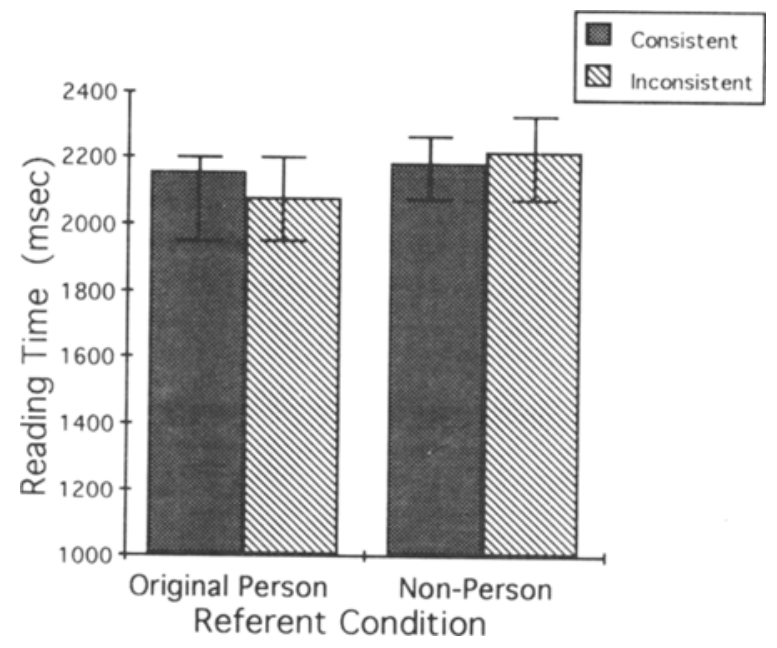

Figure 3. Mean reading times as a function of referent condition and idiom-text consistency, Experiment 3 (bars indicate standard errors of the means). 
experiment effectively eliminated this potential masking factor for analogical consistency effects.

As in Experiment 2, there was no effect of analogical consistency on reading times $\left[F_{\mathrm{s}}(1,31)=0.84 ; F_{\mathrm{i}}(1,15)=\right.$ .59 ], nor did analogical consistency interact with referent conditions $\left[F_{\mathrm{s}}(1,31)=1.22, p>.25 ; F_{\mathrm{i}}(1,15)=\right.$ $1.04, p>.30]$. Not only did we fail to find effects of analogical consistency, both the difference in the overall means for analogically consistent and inconsistent idiom completions $(2,172$ and $2,146 \mathrm{msec})$ and the difference in means within the original-referent condition $(2,160$ and $2,092 \mathrm{msec}$ ) are in the opposite direction of what would be expected if analogical consistency facilitated comprehension.

Taken together, the results of Experiments 2 and 3 suggest that even when a specific conceptual analogue for an emotion is available in a story, that conceptual analogue is not automatically accessed during idiom comprehension.

\section{GENERAL DISCUSSION}

The systematicity of idioms in various conceptual domains is striking. Surely it is not coincidental that anger, for example, can be described in such related ways as flip one's lid, blow one's stack, explode, get hot under the collar, let off steam, and so forth. At the very least, this systematicity implies that once anger has been expressed in one of these ways, people could readily coin related variants of the original idiom, whether or not that original idiom reflected any particular conceptualization of anger (e.g., as heated fluid under pressure). Even minimally motivated idiomatic expressions are commonly extended in systematic ways, as in a recent newspaper headline about the Chicago river flooding into the city's subterranean tunnels. If one recalls Carl Sandburg's poem that characterized Chicago as a "city of broad shoulders," the headline "Broad Shoulders and Wet Feet" makes perfect sense.

Other than reflecting people's penchants for systematicity in linguistic expressions, what does a particular systematicity imply about conceptual structures? The systematicity of idiomatic expressions for such concepts as anger, fear, success, and failure, among others, suggests at least three possibilities.

1. Given any set of related idiomatic expressions, people are able to recognize the relation and then may infer a basis for that relationship.

2. Conceptual metaphors for idioms are available in semantic memory and accessible in some contexts, but not in others. Specifically, they are not automatically accessed and thus do not play a necessary role in either production or comprehension.

3. Conceptual metaphors underlie idiom meanings: they not only are available, but also are automatically accessed during idiom production and comprehension, regardless of context. They play a central role in idiom use.

We will consider each of these possibilities in turn.

First, at the simplest level, systematic clusters of idiomatic expressions may imply nothing more than that peo- ple can recognize a specific relation among expressions for a given concept and infer a plausible basis for that relationship. Thus, if one were to notice that the expressions flip your lid and blow one's top referred to anger and also could be used to describe something in a pressurized container, one might infer that some aspect of the concept "anger" is analogous to heated fluid under pressure. This would not only enable a person to make judgments about the relative appropriateness of idioms in contexts, as we found in Experiment 1, but also enable people to coin new expressions based on the same set of relations. This is the most parsimonious interpretation of the results of our first experiment, in which subjects preferred idioms that were stylistically consistent with a preceding text to idioms that were stylistically inconsistent.

This interpretation suggests that people can readily infer conceptual motivations for idioms even when those motivations were irrelevant to begin with. A recent study by Keysar and Bly (1992) lends credence to this notion. Keysar gave people novel idioms in contexts that enabled them to infer the idioms' general meaning. One such idiom, culled from British English, is The goose hangs high. In one context that was given to one group of subjects, two farmers are strolling home after a long day in the fields. They express gratitude for the good growing season and the bountiful crop. At the conversation's end, one remarks to the other, "Aye, John, the goose hangs high." In an alternative context, given to a different group of subjects, the farmers bemoan the poor growing season and express dismay at the prospect of a dismal winter. At the end of this conversation, one farmer remarks to the other, "Aye, John, the goose hangs high."

If, as Lakoff and Johnson (1980) might contend, the conceptual metaphor "good is up" has a controlling influence here, the positive interpretation of the goose idiom should be more intuitively satisfying than the negative interpretation. No such preference was evident. Each group of subjects rated the idiom as "making sense," regardless of whether the meaning was positive or negative. Each group also indicated that the opposite meaning of the idiom would not make much sense. Finally, each group felt that the meaning was transparent: a majority of the subjects in each group predicted that other people would be able to get the idiom's meaning even without a supporting context. Keysar's results are reminiscent of young children's attitudes toward word meanings. As adults, we know that word meanings are assigned arbitrarily, and that what we call, say, the moon could just as well be called by any other name. For young children, a name "belongs" to its referent-a phenomenon described by Piaget (1926) as nominal realism. Perhaps we as adults retain a vestige of childhood nominal realism in our willingness to read systematicity and meaning into essentially arbitrary idiomatic word strings.

An alternative reason for systematically related idiomatic expressions within a domain is that (1) they are motivated by common conceptual cores; (2) the conceptual cores are metaphorical in nature; and (3) they are available and in certain contexts accessible in semantic 
memory. The results of Experiment 1 are certainly consistent with this hypothesis. When faced with a choice of analogically consistent or inconsistent idioms, our subjects preferred the consistent idioms, perhaps because the relevant conceptual metaphors for, say, anger, were activated during comprehension of the context stories. The data of Experiment 1, however, do not permit us to discriminate between the recognition-inference hypothesis and the availability-in-memory hypothesis.

The third and strongest implication of idiom systematicity is that conceptual metaphors underlying idiom meanings are automatically activated and accessed during production and comprehension. As Lakoff (in press) clearly puts it, "The system of conventional conceptual metaphor is mostly unconscious, automatic, and is used with no noticeable effort, just like our linguistic system and the rest of our conceptual system." The results of Experiments 2 and 3 do not confirm this hypothesis. There was no comprehension advantage for analogically consistent idioms over analogically inconsistent ones. Since the dependent measure, reading time, was sufficiently sensitive to produce a robust effect of shifting focus (original protagonist vs. other person, Experiment 2), it is unlikely that the lack of effect for analogically consistency is attributable to the particular measure that we used.

Our failure to find an effect of analogical consistency does not, of course, mean that people (1) do not have conceptual metaphors available in semantic memory, or (2) do not access those metaphors under certain circumstances. Our conclusion pertains specifically to the claim for automaticity, which we feel is certainly wrong. Under appropriate circumstances, conceptual metaphors may well be accessible and used for production or comprehension purposes. What those circumstances might be remains to be determined. Further work should enable us to specify the necessary and sufficient conditions for the activation of conceptual metaphors if, indeed, such metaphors are represented in semantic memory.

\section{REFERENCES}

Bobrow, S. A., Bell, S. M. (1973). On catching on to idiomatic expressions. Memory \& Cognition, 1, 343-346.

Garrod, S., \&ANFord, T. (1988). Thematic subjecthood and cognitive constraints on discourse structure. Journal of Pragmatics, 12. 519-534.

GIBBS, R. (1992). Metaphorical knowledge and understanding language. Paper presented at the conference on Metaphor and Cognition: Studies in Art, Linguistics, Literature, Philosophy and Psychology, University of Tel Aviv, Israel.

GLuCKSBERG, S. (1991). Beyond literal meanings: The psychology of allusion. Psychological Science, 2, 146-152.

GluCKSBERG, $\mathbf{S}$. (in press). Idiom meanings and allusional content. In C. Cacciari \& P. Tabossi (Eds.), Idioms: Representation, comprehension and production. Hillsdale, NJ: Erlbaum.

Higgins, E. T., Rholes, W. S., Jones, C. R. (1977). Category accessibility and impression formation. Joumal of Experimental Social Psychology, 13, 141-154.

KEYSAR, B., B BLY, B. (1992). Conceptual metaphors and conventional language: Why do some idioms seem transparent? Paper presented at conference on Metaphor and Cognition: Studies in Art, Linguis- tics, Literature, Philosophy and Psychology, University of Tel Aviv, Israel.

KoveCSEs, Z. (1986). Metaphors of anger, pride and love. Amsterdam: John Benjamins.

Kreuz, R. J., \& Graesser, A. C. (1991). Aspects of idiom interpretation: Comment on Nayak and Gibbs. Journal of Experimental Psychology: General, 120, 90-92.

LAKOFF, G. (1987). Women, fire and dangerous things. Chicago: University of Chicago Press.

LAKOFF, G. (in press). The contemporary theory of metaphor. In A. Ortony (Ed.), Metaphor and thought (2nd ed.). Cambridge: Cambridge University Press.

LAKofF, G., Johnson, M. (1980). Metaphors we live by. Chicago: University of Chicago Press.

McGlone, M. S., Glucksberg, S., \& Cacciari, C. (in press). Semantic productivity and idiom comprehension. Discourse Processes.

NAYAK, N. P., \&IBbS, R. W. (1990). Conceptual knowledge in the interpretation of idioms. Journal of Experimental Psychology: General, 119, 315-330.

PiAget, J. (1926). The language and thought of the child (M. Warden, Trans.). New York: Harcourt Brace.

Potts, G. R., Keenan, J. M., \& Golding, J. M. (1988). Assessing the occurrence of elaborative inferences: Lexical decision versus naming. Journal of Memory \& Language, 27, 399-415.

RATCUFF, R., \& MCKoON, G. (1986). Automatic activation of episodic information in a semantic memory task. Journal of Experimental Psychology: Learning, Memory, \& Cognition, 12, 108-115.

SRULL, T. K., \& WER, R. S. (1979). The role of category accessibility in the interpretation of information about persons: Some determinants and implications. Journal of Personality \& Social Psychology, 37, 1660-1662.

SWINNEY, D., \& CUTLER, A. (1979). The access and processing idiomatic expressions. Journal of Verbal Learning \& Verbal Behavior, 18, 523-534.

Traugott, E. C. (1975). Spatial expressions of tense and temporal sequencing: A contribution to the study of semantic fields. Semiotica, 15, 207-230.

Traugott, E. C. (1985). "Conventional" and "dead" metaphors. In W. Paprotte \& R. Dirven (Eds.). The ubiquity of metaphor (pp. 1756). Amsterdam: John Benjamins.

\section{APPENDIX A \\ Sample Materials from Experiment 1 (Idiom Choice)}

\section{Original Nayak and Gibbs Story (Original Referent)}

Susan was waiting impatiently for Chuck to pick her up from school. She had a final the next day and she wanted to get home to study. She was really tense about how she would do on the final. She was getting really hot with Chuck for his inconsiderate behavior. After an hour of waiting, Susan was reaching the limits of her patience. She was fuming and fretting, wondering how she would get home. When Chuck finally arrived with not a hint of an apology, Susan...

blew her top.

bit his head off.

\section{Other-Person Referent Version}

Susan was waiting impatiently for Chuck to pick her up from school. She had a final the next day and she wanted to get home to study. She was really tense about how she would do on the final. She was getting really hot with Chuck for his inconsiderate behavior. After an hour of waiting, Susan was reaching the limits of her patience. When Chuck finally arrived with not a hint of an apology, Susan sat in the car fuming and fretting. Chuck. 
blew his top.

bit her head off.

\section{Nonperson Referent Version}

Susan was waiting for Chuck to pick her up from school. The weather was impatient: the rain began earlier than predicted. Susan had a final the next day and she wanted to get home to study. As she waited, the winds became tense and their breath became hot. Susan realized that Chuck was being inconsiderate by keeping her waiting in this weather. After an hour of waiting, the clouds were reaching the limits of their patience and Susan was getting drenched. The winds continued their fuming and fretting, tossing Susan's hair into her face. When Chuck finally arrived with not a hint of an apology, Susan...

blew her top.

bit his head off

\section{APPENDIX B}

Sample Materials from Experiments 2 and 3 (Reading Time)

\section{Original Referent Story (Experiments 2 and 3)}

Susan waited impatiently for Chuck to pick her up from school. She had a final tomorrow and wanted to get home to study. She was really tense about how she would do on the final. She was getting really hot with Chuck for his inconsiderate behavior. After an hour of waiting, Susan reached the limits of her pa- tience. She was fuming and fretting, wondering how she would get home. Chuck eventually arrived, without a hint of an apology. Susan blew her top/bit his head off.

\section{Other-Person Referent Story (Experiment 2)}

Susan waited impatiently for Chuck to pick her up from school. She had a final tomorrow and wanted to get home to study. She was really tense about how she would do on the final. She was getting really hot with Chuck for his inconsiderate behavior. After an hour of waiting, Susan reached the limits of her patience. Chuck eventually arrived, without a hint of an apology. Susan sat down in the car, fuming and fretting. Chuck blew his top/bit her head off.

\section{Nonperson Referent Story (Experiment 3)}

Susan waited for Chuck to pick her up from school. The weather was impatient; the rain began earlier than predicted. Susan had a final tomorrow and wanted to get home to study. As she waited, the winds became tense, and their breath became hot. Chuck was being inconsiderate to make her wait in this weather. After an hour or so, the clouds reached their limits of patience. As it rained, the winds continued fuming and fretting. Chuck eventually arrived, without a hint of an apology. Susan blew her top/bit his head off.

(Manuscript received June 29, 1992; revision accepted for publication February 5, 1993.) 